\title{
A Hybrid Method for a Countable Family of Multivalued Maps, Equilibrium Problems, and Variational Inequality Problems
}

\author{
Watcharaporn Cholamjiak ${ }^{1,2}$ and Suthep Suantai ${ }^{1,2}$ \\ ${ }^{1}$ Department of Mathematics, Faculty of Science, Chiang Mai University, Chiang Mai 50200, Thailand \\ ${ }^{2}$ PERDO National Centre of Excellence in Mathematics, Faculty of Science, Mahidol University, \\ Bangkok 10400, Thailand
}

Correspondence should be addressed to Suthep Suantai, scmti005@chiangmai.ac.th

Received 26 January 2010; Accepted 21 April 2010

Academic Editor: Binggen Zhang

Copyright (C) 2010 W. Cholamjiak and S. Suantai. This is an open access article distributed under the Creative Commons Attribution License, which permits unrestricted use, distribution, and reproduction in any medium, provided the original work is properly cited.

\begin{abstract}
We introduce a new monotone hybrid iterative scheme for finding a common element of the set of common fixed points of a countable family of nonexpansive multivalued maps, the set of solutions of variational inequality problem, and the set of the solutions of the equilibrium problem in a Hilbert space. Strong convergence theorems of the purposed iteration are established.
\end{abstract}

\section{Introduction}

Let $D$ be a nonempty convex subset of a Banach spaces $E$. Let $F$ be a bifunction from $D \times D$ to $\mathbb{R}$, where $\mathbb{R}$ is the set of all real numbers. The equilibrium problem for $F$ is to find $x \in D$ such that $F(x, y) \geq 0$ for all $y \in D$. The set of such solutions is denoted by $\operatorname{EP}(F)$. The set $D$ is called proximal if for each $x \in E$, there exists an element $y \in D$ such that $\|x-y\|=d(x, D)$, where $d(x, D)=\inf \{\|x-z\|: z \in D\}$. Let $C B(D), K(D)$, and $P(D)$ denote the families of nonempty closed bounded subsets, nonempty compact subsets, and nonempty proximal bounded subsets of $D$, respectively. The Hausdorff metric on $C B(D)$ is defined by

$$
H(A, B)=\max \left\{\sup _{x \in A} d(x, B), \sup _{y \in B} d(y, A)\right\}
$$

for $A, B \in C B(D)$. A single-valued map $T: D \rightarrow D$ is called nonexpansive if $\|T x-T y\| \leq\|x-y\|$ for all $x, y \in D$. A multivalued map $T: D \rightarrow C B(D)$ is said to be nonexpansive if $H(T x, T y) \leq$ 
$\|x-y\|$ for all $x, y \in D$. An element $p \in D$ is called a fixed point of $T: D \rightarrow D$ (resp., $T: D \rightarrow C B(D)$ ) if $p=T p$ (resp., $p \in T p$ ). The set of fixed points of $T$ is denoted by $F(T)$. The mapping $T: D \rightarrow C B(D)$ is called quasi-nonexpansive [1] if $F(T) \neq \emptyset$ and $H(T x, T p) \leq\|x-p\|$ for all $x \in D$ and all $p \in F(T)$. It is clear that every nonexpansive multivalued map $T$ with $F(T) \neq \emptyset$ is quasi-nonexpansive. But there exist quasi-nonexpansive mappings that are not nonexpansive; see [2].

The mapping $T: D \rightarrow C B(D)$ is called hemicompact if, for any sequence $\left\{x_{n}\right\}$ in $D$ such that $d\left(x_{n}, T x_{n}\right) \rightarrow 0$ as $n \rightarrow \infty$, there exists a subsequence $\left\{x_{n_{k}}\right\}$ of $\left\{x_{n}\right\}$ such that $x_{n_{k}} \rightarrow p \in D$. We note that if $D$ is compact, then every multivalued mapping $T: D \rightarrow C B(D)$ is hemicompact.

A mapping $T: D \rightarrow C B(D)$ is said to satisfy Condition (I) if there is a nondecreasing function $f:[0, \infty) \rightarrow[0, \infty)$ with $f(0)=0, f(r)>0$ for $r \in(0, \infty)$ such that

$$
d(x, T x) \geq f(d(x, F(T)))
$$

for all $x \in D$.

In 1953, Mann [3] introduced the following iterative procedure to approximate a fixed point of a nonexpansive mapping $T$ in a Hilbert space $H$ :

$$
x_{n+1}=\alpha_{n} x_{n}+\left(1-\alpha_{n}\right) T x_{n}, \quad \forall n \in \mathbb{N},
$$

where the initial point $x_{0}$ is taken in $C$ arbitrarily and $\left\{\alpha_{n}\right\}$ is a sequence in $[0,1]$.

However, we note that Mann's iteration process (1.3) has only weak convergence, in general; for instance, see [4-6].

In 2003, Nakajo and Takahashi [7] introduced the method which is the so-called CQ method to modify the process (1.3) so that strong convergence is guaranteed. They also proved a strong convergence theorem for a nonexpansive mapping in a Hilbert space.

Recently, Tada and Takahashi [8] proposed a new iteration for finding a common element of the set of solutions of an equilibrium problem and the set of fixed points of a nonexpansive mapping $T$ in a Hilbert space $H$.

In 2005, Sastry and Babu [9] proved that the Mann and Ishikawa iteration schemes for multivalued map $T$ with a fixed point $p$ converge to a fixed point $q$ of $T$ under certain conditions. They also claimed that the fixed point $q$ may be different from $p$. More precisely, they proved the following result for nonexpansive multivalued map with compact domain.

In 2007, Panyanak [10] extended the above result of Sastry and Babu [9] to uniformly convex Banach spaces but the domain of $T$ remains compact.

Later, Song and Wang [11] noted that there was a gap in the proofs of Theorem 3.1 [10] and Theorem 5 [9]. They further solved/revised the gap and also gave the affirmative answer to Panyanak [10] question using the following Ishikawa iteration scheme. In the main results, domain of $T$ is still compact, which is a strong condition (see [11, Theorem 1]) and $T$ satisfies condition (I) (see [11, Theorem 1]).

In 2009, Shahzad and Zegeye [2] extended and improved the results of Panyanak [10], Sastry and Babu [9], and Song and Wang [11] to quasi-nonexpansive multivalued maps. They also relaxed compactness of the domain of $T$ and constructed an iteration scheme which removes the restriction of $T$, namely, $T p=\{p\}$ for any $p \in F(T)$. The results provided an affirmative answer to Panyanak [10] question in a more general setting. In the main results, 
$T$ satisfies Condition (I) (see [2, Theorem 2.3]) and $T$ is hemicompact and continuous (see [2, Theorem 2.5]).

A mapping $A: D \rightarrow H$ is called $\alpha$-inverse-strongly monotone [12] if there exists a positive real number $\alpha$ such that

$$
\langle A x-A y, x-y\rangle \geq \alpha\|A x-A y\|^{2}, \quad \forall x, y \in D .
$$

Remark 1.1. It is easy to see that if $A: D \rightarrow H$ is $\alpha$-inverse-strongly monotone, then it is a $(1 / \alpha)$-Lipschitzian mapping.

Let $A: D \rightarrow H$ be a mapping. The classical variational inequality problem is to find a $u \in D$ such that

$$
\langle A u, v-u\rangle \geq 0, \quad \forall v \in D
$$

The set of solutions of variational inequality (3.9) is denoted by $V I(D, A)$.

Question. How can we construct an iteration process for finding a common element of the set of solutions of an equilibrium problem, the set of solutions of a variational inequality problem, and the set of common fixed points of nonexpansive multivalued maps?

In the recent years, the problem of finding a common element of the set of solutions of equilibrium problems and the set of fixed points of single-valued nonexpansive mappings in the framework of Hilbert spaces and Banach spaces has been intensively studied by many authors; for instance, see $[8,13-20]$ and the references cited theorems.

In this paper, we introduce a monotone hybrid iterative scheme for finding a common element of the set of a common fixed points of a countable family of nonexpansive multivalued maps, the set of variational inequality, and the set of solutions of an equilibrium problem in a Hilbert space.

\section{Preliminaries}

The following lemmas give some characterizations and a useful property of the metric projection $P_{D}$ in a Hilbert space.

Let $H$ be a real Hilbert space with inner product $\langle\cdot, \cdot\rangle$ and norm $\|\cdot\|$. Let $D$ be a closed and convex subset of $H$. For every point $x \in H$, there exists a unique nearest point in $D$, denoted by $P_{D} x$, such that

$$
\left\|x-P_{D} x\right\| \leq\|x-y\|, \quad \forall y \in D .
$$

$P_{D}$ is called the metric projection of $H$ onto $D$. We know that $P_{D}$ is a nonexpansive mapping of $H$ onto $D$. 
Lemma 2.1 (see [21]). Let $D$ be a closed and convex subset of a real Hilbert space $H$ and let $P_{D}$ be the metric projection from $H$ onto $D$. Given $x \in H$ and $z \in D$, then $z=P_{D} x$ if and only if the following holds:

$$
\langle x-z, y-z\rangle \leq 0, \quad \forall y \in D
$$

Lemma 2.2 (see [7]). Let $D$ be a nonempty, closed and convex subset of a real Hilbert space $H$ and $P_{D}: H \rightarrow D$ the metric projection from $H$ onto $D$. Then the following inequality holds:

$$
\left\|y-P_{D} x\right\|^{2}+\left\|x-P_{D} x\right\|^{2} \leq\|x-y\|^{2}, \quad \forall x \in H, \forall y \in D .
$$

Lemma 2.3 (see [21]). Let $H$ be a real Hilbert space. Then the following equations hold:

(i) $\|x-y\|^{2}=\|x\|^{2}-\|y\|^{2}-2\langle x-y, y\rangle$, for all $x, y \in H$;

(ii) $\|t x+(1-t) y\|^{2}=t\|x\|^{2}+(1-t)\|y\|^{2}-t(1-t)\|x-y\|^{2}$, for all $t \in[0,1]$ and $x, y \in H$.

Lemma 2.4 (see [22]). Let $D$ be a nonempty, closed and convex subset of a real Hilbert space $H$. Given $x, y, z \in H$ and also given $a \in \mathbb{R}$, the set

$$
\left\{v \in D:\|y-v\|^{2} \leq\|x-v\|^{2}+\langle z, v\rangle+a\right\}
$$

is convex and closed.

For solving the equilibrium problem, we assume that the bifunction $F: D \times D \rightarrow \mathbb{R}$ satisfies the following conditions:

(A1) $F(x, x)=0$ for all $x \in D$;

(A2) $F$ is monotone, that is, $F(x, y)+F(y, x) \leq 0$ for all $x, y \in D$;

(A3) for each $x, y, z \in D$, limsup $\sup _{t \downarrow 0} F(t z+(1-t) x, y) \leq F(x, y)$;

(A4) $F(x, \cdot)$ is convex and lower semicontinuous for each $x \in D$.

Lemma 2.5 (see [13]). Let $D$ be a nonempty, closed and convex subset of a real Hilbert space $H$. Let $F$ be a bifunction from $D \times D$ to $\mathbb{R}$ satisfying (A1)-(A4) and let $r>0$ and $x \in H$. Then, there exists $z \in D$ such that

$$
F(z, y)+\frac{1}{r}\langle y-z, z-x\rangle \geq 0, \quad \forall y \in D
$$

Lemma 2.6 (see [18]). For $r>0, x \in H$, defined a mapping $T_{r}: H \rightarrow D$ as follows:

$$
T_{r}(x)=\left\{z \in D: F(z, y)+\frac{1}{r}\langle y-z, z-x\rangle \geq 0, \forall y \in D\right\} .
$$

Then the following holds:

(1) $T_{r}$ is a single value; 
(2) $T_{r}$ is firmly nonexpansive, that is, for any $x, y \in H$,

$$
\left\|T_{r} x-T_{r} y\right\|^{2} \leq\left\langle T_{r} x-T_{r} y, x-y\right\rangle
$$

(3) $F\left(T_{r}\right)=E P(F)$;

(4) $E P(F)$ is closed and convex.

In the context of the variational inequality problem,

$$
u \in V I(D, A) \Longleftrightarrow u=P_{D}(u-\lambda A u), \quad \forall \lambda>0
$$

A set-valued mapping $T: H \rightarrow 2^{H}$ is said to be monotone if for all $x, y \in H, f \in T x$, and $g \in T y$ imply that $\langle f-g, x-y\rangle \geq 0$. A monotone mapping $T: H \rightarrow H$ is said to be maximal [23] if the graph $G(T)$ of $T$ is not properly contained in the graph of any other monotone mapping. It is known that a monotone mapping is maximal if and only if for $(x, f) \in H \times H$, $\langle f-g, x-y\rangle \geq 0, \forall(y, g) \in G(T)$ imply that $f \in T x$. Let $A: D \rightarrow H$ be an inverse strongly monotone mapping and let $N_{D} v$ be the normal cone to $D$ at $v \in D$, that is,

$$
N_{D} v=\{w \in H:\langle v-u, w\rangle \geq 0, \forall u \in D\}
$$

and define

$$
T v= \begin{cases}A v+N_{D} v, & v \in D, \\ \emptyset, & v \notin D .\end{cases}
$$

Then $T$ is maximal monotone and $0 \in T v$ if and only if $v \in V I(D, A)$ (see, e.g., [24]).

In general, the fixed point set of a nonexpansive multivalued map $T$ is not necessary to be closed and convex (see [25, Example 3.2]). In the next Lemma, we show that $F(T)$ is closed and convex under the assumption that $T p=\{p\}$ for all $p \in F(T)$.

Lemma 2.7. Let $D$ be a closed and convex subset of a real Hilbert space $H$. Let $T: D \rightarrow C B(D)$ be a nonexpansive multivalued map with $F(T) \neq \emptyset$ and $T p=\{p\}$ for each $p \in F(T)$. Then $F(T)$ is a closed and convex subset of $D$.

Proof. First, we will show that $F(T)$ is closed. Let $\left\{x_{n}\right\}$ be a sequence in $F(T)$ such that $x_{n} \rightarrow x$ as $n \rightarrow \infty$. We have

$$
\begin{aligned}
d(x, T x) & \leq d\left(x, x_{n}\right)+d\left(x_{n}, T x\right) \\
& \leq d\left(x, x_{n}\right)+H\left(T x_{n}, T x\right) \\
& \leq 2 d\left(x, x_{n}\right) .
\end{aligned}
$$


It follows that $d(x, T x)=0$, so $x \in F(T)$. Next, we show that $F(T)$ is convex. Let $p=t p_{1}+(1-$ t) $p_{2}$ where $p_{1}, p_{2} \in F(T)$ and $t \in(0,1)$. Let $z \in T p$; by Lemma 2.3, we have

$$
\begin{aligned}
\|p-z\|^{2} & =\left\|t\left(z-p_{1}\right)+(1-t)\left(z-p_{2}\right)\right\|^{2} \\
& =t\left\|z-p_{1}\right\|^{2}+(1-t)\left\|z-p_{2}\right\|^{2}-t(1-t)\left\|p_{1}-p_{2}\right\|^{2} \\
& =t d\left(z, T p_{1}\right)^{2}+(1-t) d\left(z, T p_{2}\right)^{2}-t(1-t)\left\|p_{1}-p_{2}\right\|^{2} \\
& \leq t H\left(T p, T p_{1}\right)^{2}+(1-t) H\left(T p, T p_{2}\right)^{2}-t(1-t)\left\|p_{1}-p_{2}\right\|^{2} \\
& \leq t\left\|p-p_{1}\right\|^{2}+(1-t)\left\|p-p_{2}\right\|^{2}-t(1-t)\left\|p_{1}-p_{2}\right\|^{2} \\
& =t(1-t)^{2}\left\|p_{1}-p_{2}\right\|^{2}+(1-t) t^{2}\left\|p_{1}-p_{2}\right\|^{2}-t(1-t)\left\|p_{1}-p_{2}\right\|^{2} \\
& =0 .
\end{aligned}
$$

Hence $p=z$. Therefore, $p \in F(T)$.

\section{Main Results}

In the following theorem, we introduce a new monotone hybrid iterative scheme for finding a common element of the set of a common fixed points of a countable family of nonexpansive multivalued maps, the set of variational inequality, and the set of solutions of an equilibrium problem in a Hilbert space, and we prove strong convergence theorem without the condition (I).

Theorem 3.1. Let $D$ be a nonempty, closed and convex subset of a real Hilbert space $H$. Let $F$ be a bifunction from $D \times D$ to $\mathbb{R}$ satisfying (A1)-(A4), let $A: D \rightarrow H$ be an $\alpha$-inverse strongly monotone mapping, and let $T_{i}: D \rightarrow C B(D)$ be nonexpansive multivalued maps for all $i \in \mathbb{N}$ with $\Omega:=\bigcap_{i=1}^{\infty} F\left(T_{i}\right) \cap E P(F) \cap V I(D, A) \neq \emptyset$ and $T_{i} p=\{p\}, \forall p \in \bigcap_{i=1}^{\infty} F\left(T_{i}\right)$. Assume that $\alpha_{i, n} \in[0,1)$ with $\limsup \sup _{n \rightarrow \infty} \alpha_{i, n}<1$ for all $i \in \mathbb{N},\left\{r_{n}\right\} \subset[b, \infty)$ for some $b \in(0, \infty)$, and $\left\{\lambda_{n}\right\} \subset[c, d]$ for some $c, d \in(0,2 \alpha)$. For an initial point $x_{0} \in H$ with $C_{1}=D$ and $x_{1}=P_{C_{1}} x_{0}$, let $\left\{x_{n}\right\},\left\{y_{n}\right\},\left\{s_{i, n}\right\}$, and $\left\{u_{n}\right\}$ be sequences generated by

$$
\begin{gathered}
F\left(u_{n}, y\right)+\frac{1}{r_{n}}\left\langle y-u_{n}, u_{n}-x_{n}\right\rangle \geq 0, \quad \forall y \in D, \\
y_{n}=P_{D}\left(u_{n}-\lambda_{n} A u_{n}\right), \\
s_{i, n}=\alpha_{i, n} y_{n}+\left(1-\alpha_{i, n}\right) z_{i, n}, \\
C_{i, n+1}=\left\{z \in C_{i, n}:\left\|s_{i, n}-z\right\| \leq\left\|y_{n}-z\right\| \leq\left\|x_{n}-z\right\|\right\}, \\
C_{n+1}=\bigcap_{i=1}^{\infty} C_{i, n+1}, \\
x_{n+1}=P_{C_{n+1}} x_{0}, \quad \forall n \in \mathbb{N},
\end{gathered}
$$

where $z_{i, n} \in T_{i} y_{n}$. Then, $\left\{x_{n}\right\},\left\{y_{n}\right\}$, and $\left\{u_{n}\right\}$ converge strongly to $z_{0}=P_{\Omega} x_{0}$. 
Proof. We split the proof into six steps.

Step 1. Show that $P_{C_{n+1}} x_{0}$ is well defined for every $x_{0} \in H$.

Since $0<c \leq \lambda_{n} \leq d<2 \alpha$ for all $n \in \mathbb{N}$, we get that $P_{C}\left(I-\lambda_{n} A\right)$ is nonexpansive for all $n \in \mathbb{N}$. Hence, $\bigcap_{n=1}^{\infty} F\left(P_{C}\left(I-\lambda_{n} A\right)\right)=V I(D, A)$ is closed and convex. By Lemma 2.6(4), we know that $E P(F)$ is closed and convex. By Lemma 2.7, we also know that $\bigcap_{i=1}^{\infty} F\left(T_{i}\right)$ is closed and convex. Hence, $\Omega:=\bigcap_{i=1}^{\infty} F\left(T_{i}\right) \cap E P(F) \cap V I(D, A)$ is a nonempty, closed and convex set. By Lemma 2.4, we see that $C_{i, n+1}$ is closed and convex for all $i, n \in \mathbb{N}$. This implies that $C_{n+1}$ is also closed and convex. Therefore, $P_{C_{n+1}} x_{0}$ is well defined. Let $p \in \Omega$ and $i \in \mathbb{N}$. From $u_{n}=T_{r_{n}} x_{n}$, we have

$$
\left\|u_{n}-p\right\|=\left\|T_{r_{n}} x_{n}-T_{r_{n}} p\right\| \leq\left\|x_{n}-p\right\|
$$

for every $n \geq 0$. From this, we have

$$
\begin{aligned}
\left\|s_{i, n}-p\right\| & =\left\|\alpha_{i, n} y_{n}+\left(1-\alpha_{i, n}\right) z_{i, n}-p\right\| \\
& \leq \alpha_{i, n}\left\|y_{n}-p\right\|+\left(1-\alpha_{i, n}\right)\left\|z_{i, n}-p\right\| \\
& \leq \alpha_{i, n}\left\|y_{n}-p\right\|+\left(1-\alpha_{i, n}\right) d\left(z_{i, n}, T_{i} p\right) \\
& \leq \alpha_{i, n}\left\|y_{n}-p\right\|+\left(1-\alpha_{i, n}\right) H\left(T_{i} y_{n}, T_{i} p\right) \\
& \leq\left\|y_{n}-p\right\| \\
& =\left\|P_{D}\left(u_{n}-\lambda_{n} A u_{n}\right)-P_{D}\left(p-\lambda_{n} A p\right)\right\| \\
& \leq\left\|u_{n}-p\right\| \\
& \leq\left\|x_{n}-p\right\| .
\end{aligned}
$$

So, we have $p \in C_{i, n+1}$, hence $\Omega \subset C_{i, n+1}, \forall i \in \mathbb{N}$. This shows that $\Omega \subset C_{n+1} \subset C_{n}$.

Step 2. Show that $\lim _{n \rightarrow \infty}\left\|x_{n}-x_{0}\right\|$ exists.

Since $\Omega$ is a nonempty closed convex subset of $H$, there exists a unique $v \in \Omega$ such that

$$
z_{0}=P_{\Omega} x_{0}
$$

From $x_{n}=P_{C_{n}} x_{0}, C_{n+1} \subset C_{n}$ and $x_{n+1} \in C_{n}, \forall n \geq 0$, we get

$$
\left\|x_{n}-x_{0}\right\| \leq\left\|x_{n+1}-x_{0}\right\|, \quad \forall n \geq 0
$$

On the other hand, as $\Omega \subset C_{n}$, we obtain

$$
\left\|x_{n}-x_{0}\right\| \leq\left\|z_{0}-x_{0}\right\|, \quad \forall n \geq 0
$$


It follows that the sequence $\left\{x_{n}\right\}$ is bounded and nondecreasing. Therefore, $\lim _{n \rightarrow \infty}\left\|x_{n}-x_{0}\right\|$ exists.

Step 3. Show that $x_{n} \rightarrow q \in D$ as $n \rightarrow \infty$.

For $m>n$, by the definition of $C_{n}$, we see that $x_{m}=P_{C_{m}} x_{0} \in C_{m} \subset C_{n}$. By Lemma 2.2, we get

$$
\left\|x_{m}-x_{n}\right\|^{2} \leq\left\|x_{m}-x_{0}\right\|^{2}-\left\|x_{n}-x_{0}\right\|^{2} .
$$

From Step 2, we obtain that $\left\{x_{n}\right\}$ is Cauchy. Hence, there exists $q \in D$ such that $x_{n} \rightarrow q$ as $n \rightarrow \infty$.

Step 4. Show that $q \in F$.

From Step 3, we get

$$
\left\|x_{n+1}-x_{n}\right\| \longrightarrow 0
$$

as $n \rightarrow \infty$. Since $x_{n+1} \in C_{n+1} \subset C_{n}$, we have

$$
\left\|s_{i, n}-x_{n}\right\| \leq\left\|s_{i, n}-x_{n+1}\right\|+\left\|x_{n+1}-x_{n}\right\| \leq 2\left\|x_{n+1}-x_{n}\right\| \longrightarrow 0
$$

as $n \rightarrow \infty$ for all $i \in \mathbb{N}$,

$$
\left\|y_{n}-x_{n}\right\| \leq\left\|y_{n}-x_{n+1}\right\|+\left\|x_{n+1}-x_{n}\right\| \leq 2\left\|x_{n+1}-x_{n}\right\| \longrightarrow 0
$$

as $n \rightarrow \infty$. Hence, $y_{n} \rightarrow q$ as $n \rightarrow \infty$. It follows from (3.9) and (3.10) that

$$
\left\|z_{i, n}-y_{n}\right\|=\frac{1}{1-\alpha_{i, n}}\left\|s_{i, n}-y_{n}\right\| \longrightarrow 0
$$

as $n \rightarrow \infty$ for all $i \in \mathbb{N}$. For each $i \in \mathbb{N}$, we have

$$
\begin{aligned}
d\left(q, T_{i} q\right) & \leq\left\|q-y_{n}\right\|+\left\|y_{n}-z_{i, n}\right\|+d\left(z_{i, n}, T_{i} q\right) \\
& \leq\left\|q-y_{n}\right\|+\left\|y_{n}-z_{i, n}\right\|+H\left(T_{i} y_{n}, T_{i} q\right) \\
& \leq\left\|q-y_{n}\right\|+\left\|y_{n}-z_{i, n}\right\|+\left\|y_{n}-q\right\| .
\end{aligned}
$$

From (3.11), we obtain $d\left(q, T_{i} q\right)=0$. Hence $q \in F$. 
Step 5. Show that $q \in E P(F)$.

By the nonexpansiveness of $P_{D}$ and the inverse strongly monotonicity of $A$, we obtain

$$
\begin{aligned}
\left\|y_{n}-p\right\|^{2} & \leq\left\|u_{n}-\lambda_{n} A u_{n}-\left(p-\lambda_{n} A p\right)\right\|^{2} \\
& \leq\left\|u_{n}-p\right\|^{2}+\lambda_{n}\left(\lambda_{n}-2 \alpha\right)\left\|A u_{n}-A p\right\|^{2} \\
& =\left\|T_{r_{n}} x_{n}-T_{r_{n}} p\right\|^{2}+\lambda_{n}\left(\lambda_{n}-2 \alpha\right)\left\|A u_{n}-A p\right\|^{2} \\
& \leq\left\|x_{n}-p\right\|^{2}+c(d-2 \alpha)\left\|A u_{n}-A p\right\|^{2} .
\end{aligned}
$$

This implies

$$
\begin{aligned}
c(2 \alpha-d)\left\|A u_{n}-A p\right\|^{2} & \leq\left\|x_{n}-p\right\|^{2}-\left\|y_{n}-p\right\|^{2} \\
& \leq\left\|x_{n}-y_{n}\right\|\left(\left\|x_{n}-p\right\|+\left\|y_{n}-p\right\|\right) .
\end{aligned}
$$

It follows from (3.10) that

$$
\lim _{n \rightarrow \infty}\left\|A u_{n}-A p\right\|=0
$$

Since $P_{D}$ is firmly nonexpansive, we have

$$
\begin{aligned}
\left\|y_{n}-p\right\|^{2}= & \left\|P_{D}\left(u_{n}-\lambda_{n} A u_{n}\right)-P_{D}\left(p-\lambda_{n} A p\right)\right\|^{2} \\
\leq & \left.\left\langle u_{n}-\lambda_{n} A u_{n}\right)-\left(p-\lambda_{n} A p\right), y_{n}-p\right\rangle \\
= & \frac{1}{2}\left(\left\|\left(u_{n}-\lambda_{n} A u_{n}\right)-\left(p-\lambda_{n} A p\right)\right\|^{2}\right. \\
& \left.\quad+\left\|y_{n}-p\right\|^{2}-\left\|\left(u_{n}-\lambda_{n} A u_{n}\right)-\left(p-\lambda_{n} A p\right)-\left(y_{n}-p\right)\right\|^{2}\right) \\
\leq & \frac{1}{2}\left(\left\|u_{n}-p\right\|^{2}+\left\|y_{n}-p\right\|^{2}-\left\|\left(u_{n}-y_{n}\right)-\lambda_{n}\left(A u_{n}-A p\right)\right\|^{2}\right) \\
\leq & \frac{1}{2}\left(\left\|x_{n}-p\right\|^{2}+\left\|y_{n}-p\right\|^{2}-\left\|u_{n}-y_{n}\right\|^{2}+2 \lambda_{n}\left\langle u_{n}-y_{n}, A u_{n}-A p\right\rangle\right) \\
\leq & \frac{1}{2}\left(\left\|x_{n}-p\right\|^{2}+\left\|y_{n}-p\right\|^{2}-\left\|u_{n}-y_{n}\right\|^{2}+2 \lambda_{n}\left\|u_{n}-y_{n}\right\|\left\|A u_{n}-A p\right\|\right) .
\end{aligned}
$$

This implies that

$$
\left\|y_{n}-p\right\|^{2} \leq\left\|x_{n}-p\right\|^{2}-\left\|u_{n}-y_{n}\right\|^{2}+2 \lambda_{n}\left\|u_{n}-y_{n}\right\|\left\|A u_{n}-A p\right\| .
$$


It follows that

$$
\begin{aligned}
\left\|u_{n}-y_{n}\right\|^{2} \leq & \left\|x_{n}-y_{n}\right\|\left(\left\|x_{n}-p\right\|+\left\|y_{n}-p\right\|\right) \\
& +2 d\left\|u_{n}-y_{n}\right\|\left\|A u_{n}-A p\right\| .
\end{aligned}
$$

From (3.10) and (3.15), we get

$$
\lim _{n \rightarrow \infty}\left\|u_{n}-y_{n}\right\|=0
$$

It follows from (3.10) and (3.19) that

$$
\lim _{n \rightarrow \infty}\left\|u_{n}-x_{n}\right\|=0
$$

Since $u_{n}=T_{r_{n}} x_{n}$, we have

$$
F\left(u_{n}, y\right)+\frac{1}{r_{n}}\left\langle y-u_{n}, u_{n}-x_{n}\right\rangle \geq 0, \quad \forall y \in D
$$

From the monotonicity of $F$, we have

$$
\frac{1}{r_{n}}\left\langle y-u_{n}, u_{n}-x_{n}\right\rangle \geq F\left(y, u_{n}\right), \quad \forall y \in D,
$$

hence

$$
\left\langle y-u_{n}, \frac{u_{n}-x_{n}}{r_{n}}\right\rangle \geq F\left(y, u_{n}\right), \quad \forall y \in D
$$

From (3.20) and condition (A4), we have

$$
0 \geq F(y, q), \quad \forall y \in \mathrm{D} .
$$

For $t$ with $0<t \leq 1$ and $y \in D$, let $y_{t}=t y+(1-t) q$. Since $y, q \in D$ and $D$ is convex, then $y_{t} \in D$ and hence $F\left(y_{t}, q\right) \leq 0$. So, we have

$$
0=F\left(y_{t}, y_{t}\right) \leq t F\left(y_{t}, y\right)+(1-t) F\left(y_{t}, q\right) \leq t F\left(y_{t}, y\right)
$$

Dividing by $t$, we obtain

$$
F\left(y_{t}, y\right) \geq 0, \quad \forall y \in D
$$


Discrete Dynamics in Nature and Society

Letting $t \downarrow 0$ and from (A3), we get

$$
F(q, y) \geq 0, \quad \forall y \in D
$$

Therefore, we obtain $q \in E P(F)$.

Step 6. Show that $q \in V I(D, A)$.

Since $T$ is the maximal monotone mapping defined by (2.10),

$$
T x= \begin{cases}A x+N_{D} x, & x \in D, \\ \emptyset, & x \notin D .\end{cases}
$$

For any given $(x, u) \in G(T)$, hence $u-A x \in N_{D} x$. It follows that

$$
\left\langle x-y_{n}, u-A x\right\rangle \geq 0 \text {. }
$$

On the other hand, since $y_{n}=P_{D}\left(u_{n}-\lambda_{n} A u_{n}\right)$, we have

$$
\left\langle x-y_{n}, y_{n}-\left(u_{n}-\lambda_{n} A u_{n}\right)\right\rangle \geq 0,
$$

and so

$$
\left\langle x-y_{n}, \frac{y_{n}-u_{n}}{\lambda_{n}}+A u_{n}\right\rangle \geq 0
$$

From (3.29), (3.31), and the $\alpha$-inverse monotonicity of $A$, we have

$$
\begin{aligned}
\left\langle x-y_{n}, u\right\rangle & \geq\left\langle x-y_{n}, A x\right\rangle \\
& \geq\left\langle x-y_{n}, A x\right\rangle-\left\langle x-y_{n}, \frac{y_{n}-u_{n}}{\lambda_{n}}+A u_{n}\right\rangle \\
& =\left\langle x-y_{n}, A x-A y_{n}\right\rangle+\left\langle x-y_{n}, A y_{n}-A u_{n}\right\rangle-\left\langle x-y_{n}, \frac{y_{n}-u_{n}}{\lambda_{n}}\right\rangle \\
& \geq\left\langle x-y_{n}, A y_{n}-A u_{n}\right\rangle-\left\langle x-y_{n}, \frac{y_{n}-u_{n}}{\lambda_{n}}\right\rangle .
\end{aligned}
$$

It follows that

$$
\lim _{n \rightarrow \infty}\left\langle x-y_{n}, u\right\rangle=\langle x-q, u\rangle \geq 0
$$

Again since $T$ is maximal monotone, hence $0 \in T q$. This shows that $q \in V I(D, A)$. 
Step 7. Show that $q=z_{0}=P_{\Omega} x_{0}$.

Since $x_{n}=P_{C_{n}} x_{0}$ and $\Omega \subset C_{n}$, we obtain

$$
\left\langle x_{0}-x_{n}, x_{n}-p\right\rangle \geq 0 \quad \forall p \in \Omega
$$

By taking the limit in (3.34), we obtain

$$
\left\langle x_{0}-q, q-p\right\rangle \geq 0 \quad \forall p \in \Omega
$$

This shows that $q=P_{\Omega} x_{0}=z_{0}$.

From Steps 3 to 5 , we obtain that $\left\{x_{n}\right\},\left\{y_{n}\right\}$, and $\left\{u_{n}\right\}$ converge strongly to $z_{0}=P_{\Omega} x_{0}$. This completes the proof.

Theorem 3.2. Let $D$ be a nonempty, closed and convex subset of a real Hilbert space $H$. Let $T_{i}$ : $D \rightarrow C B(D)$ be nonexpansive multivalued maps for all $i \in \mathbb{N}$ with $\Omega:=\bigcap_{i=1}^{\infty} F\left(T_{i}\right) \cap V I(D, A) \neq \emptyset$ and $T_{i} p=\{p\}$, for all $p \in \bigcap_{i=1}^{\infty} F\left(T_{i}\right)$. Assume that $\alpha_{i, n} \in[0,1)$ with $\limsup _{n \rightarrow \infty} \alpha_{i, n}<1$ and $\left\{\lambda_{n}\right\} \subset[c, d]$ for some $c, d \in(0,2 \alpha)$. For an initial point $x_{0} \in H$ with $C_{1}=D$ and $x_{1}=P_{C_{1}} x_{0}$, let $\left\{x_{n}\right\},\left\{y_{n}\right\}$, and $\left\{s_{i, n}\right\}$ be sequences generated by

$$
\begin{aligned}
y_{n} & =P_{D}\left(x_{n}-\lambda_{n} A x_{n}\right), \\
s_{i, n} & =\alpha_{i, n} y_{n}+\left(1-\alpha_{i, n}\right) z_{i, n}, \\
C_{i, n+1} & =\left\{z \in C_{i, n}:\left\|s_{i, n}-z\right\| \leq\left\|y_{n}-z\right\| \leq\left\|x_{n}-z\right\|\right\}, \\
C_{n+1} & =\bigcap_{i=1}^{\infty} C_{i, n+1}, \\
x_{n+1} & =P_{C_{n+1}} x_{0}, \quad \forall n \in \mathbb{N},
\end{aligned}
$$

where $z_{i, n} \in T_{i} y_{n}$. Then, $\left\{x_{n}\right\}$ and $\left\{y_{n}\right\}$ converge strongly to $z_{0}=P_{\Omega} x_{0}$.

Proof. Putting $F(x, y)=0$ for all $x, y \in D$ in Theorem 3.1, we obtain the desired result directly from Theorem 3.1.

Theorem 3.3. Let $D$ be a nonempty, closed and convex subset of a real Hilbert space $H$. Let $T_{i}: D \rightarrow$ $C B(D)$ be nonexpansive multivalued maps for all $i \in \mathbb{N}$ with $\Omega:=\bigcap_{i=1}^{\infty} F\left(T_{i}\right) \neq \emptyset$ and $T_{i} p=\{p\}$, for all $p \in \bigcap_{i=1}^{\infty} F\left(T_{i}\right)$. Assume that $\alpha_{i, n} \in[0,1)$ with $\limsup _{n \rightarrow \infty} \alpha_{i, n}<1$. For an initial point $x_{0} \in H$ with $C_{1}=D$ and $x_{1}=P_{C_{1}} x_{0}$, let $\left\{x_{n}\right\}$ and $\left\{s_{i, n}\right\}$ be sequences generated by

$$
\begin{aligned}
s_{i, n} & =\alpha_{i, n} x_{n}+\left(1-\alpha_{i, n}\right) z_{i, n}, \\
C_{i, n+1} & =\left\{z \in C_{i, n}:\left\|s_{n}-z\right\| \leq\left\|x_{n}-z\right\|\right\}, \\
C_{n+1} & =\bigcap_{i=1}^{\infty} C_{i, n+1}, \\
x_{n+1} & =P_{C_{n+1}} x_{0}, \quad \forall n \in \mathbb{N},
\end{aligned}
$$

where $z_{i, n} \in T_{i} y_{n}$. Then, $\left\{x_{n}\right\}$ converge strongly to $z_{0}=P_{\Omega} x_{0}$. 
Proof. Putting $A=0$ in Theorem 3.2, we obtain the desired result directly from Theorem 3.2.

\section{Acknowledgments}

This research is supported by the Centre of Excellence in Mathematics and the Graduate School of Chiang Mai University.

\section{References}

[1] C. Shiau, K. K. Tan, and C. S. Wong, "Quasi-nonexpansive multi-valued maps and selections," Fundamenta Mathematicae, vol. 87, pp. 109-119, 1975.

[2] N. Shahzad and H. Zegeye, "On Mann and Ishikawa iteration schemes for multi-valued maps in Banach spaces," Nonlinear Analysis: Theory, Methods E Applications, vol. 71, no. 3-4, pp. 838-844, 2009.

[3] W. R. Mann, "Mean value methods in iteration," Proceedings of the American Mathematical Society, vol. 4, pp. 506-510, 1953.

[4] H. H. Bauschke, E. Matoušková, and S. Reich, "Projection and proximal point methods: convergence results and counterexamples," Nonlinear Analysis: Theory, Methods \& Applications, vol. 56, no. 5, pp. 715-738, 2004.

[5] A. Genel and J. Lindenstrauss, "An example concerning fixed points," Israel Journal of Mathematics, vol. 22, no. 1, pp. 81-86, 1975.

[6] S. Reich, "Weak convergence theorems for nonexpansive mappings in Banach spaces," Journal of Mathematical Analysis and Applications, vol. 67, no. 2, pp. 274-276, 1979.

[7] K. Nakajo and W. Takahashi, "Strong convergence theorems for nonexpansive mappings and nonexpansive semigroups," Journal of Mathematical Analysis and Applications, vol. 279, no. 2, pp. 372 379, 2003.

[8] A. Tada and W. Takahashi, "Weak and strong convergence theorems for a nonexpansive mapping and an equilibrium problem," Journal of Optimization Theory and Applications, vol. 133, no. 3, pp. 359-370, 2007.

[9] K. P. R. Sastry and G. V. R. Babu, “Convergence of Ishikawa iterates for a multi-valued mapping with a fixed point," Czechoslovak Mathematical Journal, vol. 55, no. 4, pp. 817-826, 2005.

[10] B. Panyanak, "Mann and Ishikawa iterative processes for multivalued mappings in Banach spaces," Computers \& Mathematics with Applications, vol. 54, no. 6, pp. 872-877, 2007.

[11] Y. Song and H. Wang, "Erratum to Mann and Ishikawa iterative process for multivalued mappings in Banach spaces," Comput. Math. Appl., vol. 55, no. 6, pp. 2999-3002, 2008.

[12] F. E. Browder and W. V. Petryshyn, "Construction of fixed points of nonlinear mappings in Hilbert space," Journal of Mathematical Analysis and Applications, vol. 20, pp. 197-228, 1967.

[13] E. Blum and W. Oettli, "From optimization and variational inequalities to equilibrium problems," The Mathematics Student, vol. 63, no. 1-4, pp. 123-145, 1994.

[14] L.-C. Ceng and J.-C. Yao, "A hybrid iterative scheme for mixed equilibrium problems and fixed point problems," Journal of Computational and Applied Mathematics, vol. 214, no. 1, pp. 186-201, 2008.

[15] P. Cholamjiak, "A hybrid iterative scheme for equilibrium problems, variational inequality problems, and fixed point problems in Banach spaces," Fixed Point Theory and Applications, vol. 2009, Article ID 719360, 18 pages, 2009.

[16] P. Cholamjiak and S. Suantai, "A new hybrid algorithm for variational inclusions, generalized equilibrium problems, and a finite family of quasi-nonexpansive mappings," Fixed Point Theory and Applications, vol. 2009, Article ID 350979, 20 pages, 2009.

[17] W. Cholamjiak and S. Suantai, "Monotone hybrid projection algorithms for an infinitely countable family of Lipschitz generalized asymptotically quasi-nonexpansive mappings," Abstract and Applied Analysis, vol. 2009, Article ID 297565, 16 pages, 2009.

[18] P. L. Combettes and S. A. Hirstoaga, "Equilibrium programming in Hilbert spaces," Journal of Nonlinear and Convex Analysis, vol. 6, no. 1, pp. 117-136, 2005.

[19] A. Kangtunyakarn and S. Suantai, "Hybrid iterative scheme for generalized equilibrium problems and fixed point problems of finite family of nonexpansive mappings," Nonlinear Analysis: Hybrid Systems, vol. 3, no. 3, pp. 296-309, 2009. 
[20] J.-W. Peng, Y.-C. Liou, and J.-C. Yao, “An iterative algorithm combining viscosity method with parallel method for a generalized equilibrium problem and strict pseudocontractions," Fixed Point Theory and Applications, vol. 2009, Article ID 794178, 21 pages, 2009.

[21] G. Marino and H.-K. Xu, "Weak and strong convergence theorems for strict pseudo-contractions in Hilbert spaces," Journal of Mathematical Analysis and Applications, vol. 329, no. 1, pp. 336-346, 2007.

[22] T.-H. Kim and H.-K. Xu, "Strong convergence of modified Mann iterations for asymptotically nonexpansive mappings and semigroups," Nonlinear Analysis: Theory, Methods \& Applications, vol. 64, no. 5, pp. 1140-1152, 2006.

[23] R. T. Rockafellar, "On the maximality of sums of nonlinear monotone operators," Transactions of the American Mathematical Society, vol. 149, pp. 75-88, 1970.

[24] H. Iiduka and W. Takahashi, "Strong convergence theorems for nonexpansive mappings and inversestrongly monotone mappings," Nonlinear Analysis: Theory, Methods E Applications, vol. 61, no. 3, pp. 341-350, 2005.

[25] A. R. Khan, "Properties of fixed point set of a multivalued map," Journal of Applied Mathematics and Stochastic Analysis, vol. 2005, no. 3, pp. 323-331, 2005. 


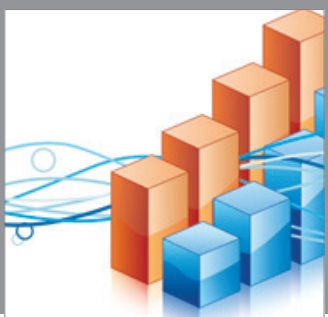

Advances in

Operations Research

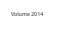

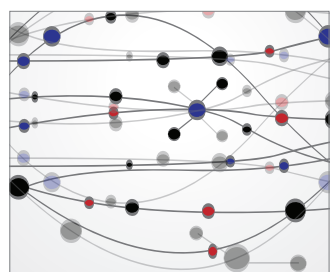

\section{The Scientific} World Journal
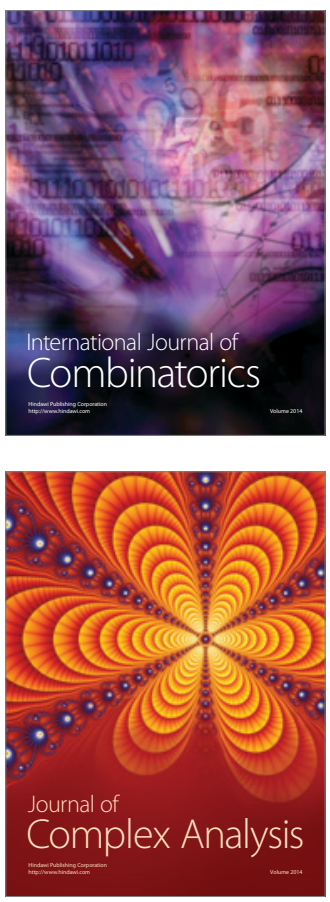

International Journal of

Mathematics and

Mathematical

Sciences
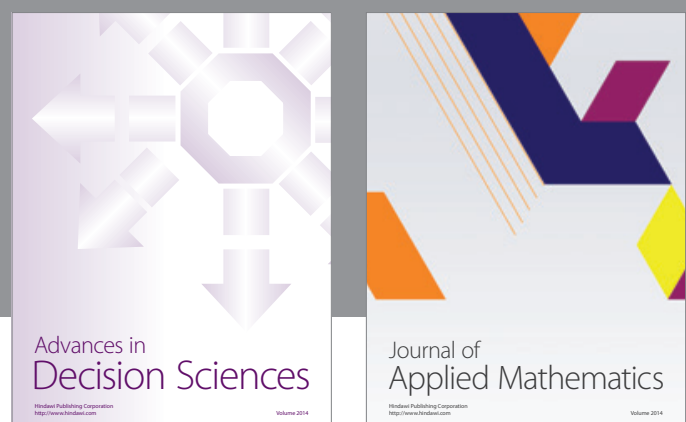

Journal of

Applied Mathematics
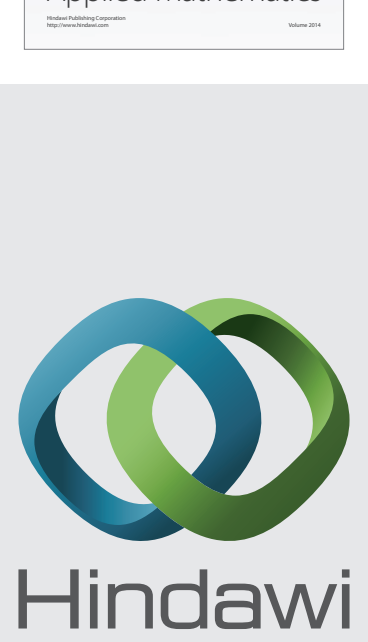

Submit your manuscripts at http://www.hindawi.com
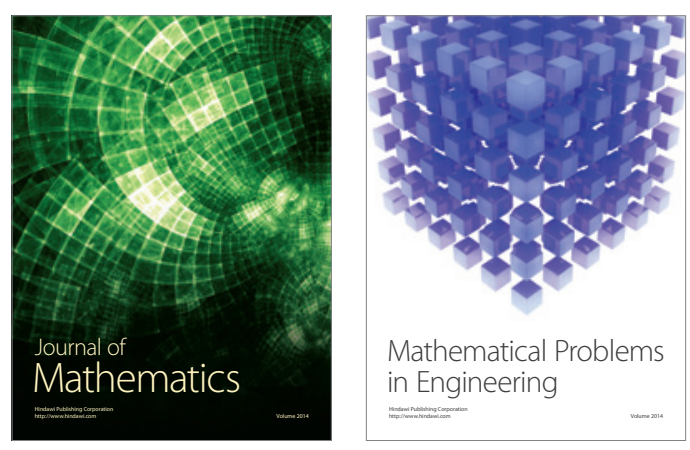

Mathematical Problems in Engineering
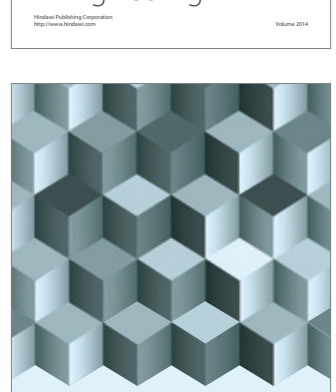

Journal of

Function Spaces
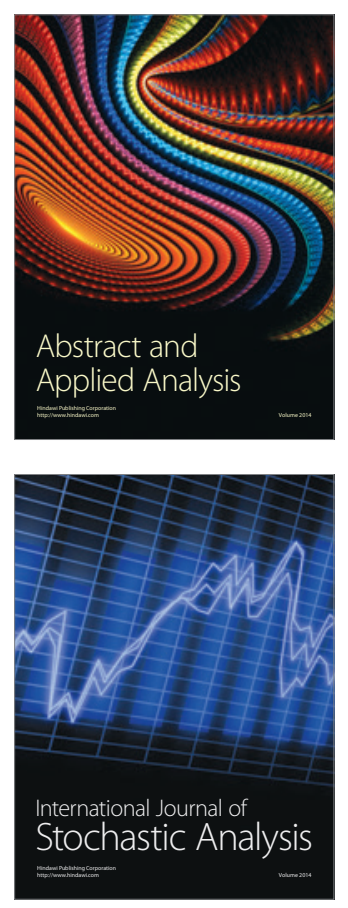

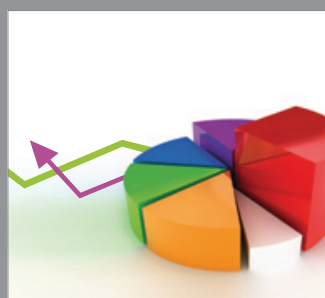

ournal of

Probability and Statistics

Promensencen
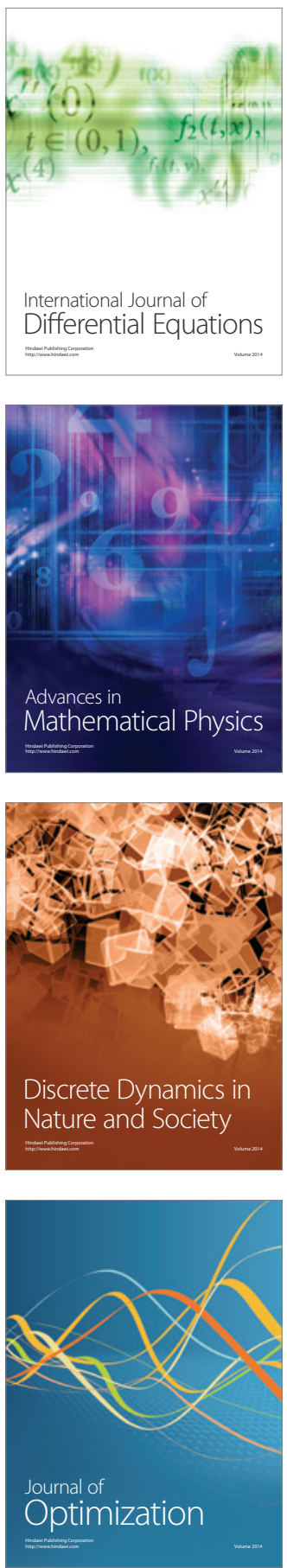